\title{
Investigating the proposed sanctuary near the volcanic Lago di Venere, Pantelleria, Italy, in 2014 and 2015
}

\author{
Carrie Ann Murray,*, Clive Vella ${ }^{2}$, Thomas M. Urban ${ }^{3}$ \\ $\&$ Maxine Anastasi ${ }^{4}$
}

The longue durée of human activity on the island of Pantelleria represents an important locus of ancient cultural interaction in the Strait of Sicily. This narrow channel in the central Mediterranean has played a major and continuous role in human relations between Italy, Sicily and North Africa since the Neolithic period. Use or control of the Pantelleria has been pivotal for a number of cultures over time, each leaving a lasting impression on the landscape and the people of the island (Figure 1). The volcanic geology of Pantelleria has determined the shape of its landscape and is responsible for the creation of the collapsedcaldera basin and lake that form the study area of this project. The Brock University Archaeological Project at Pantelleria (BUAPP) is working in the Lago di Venere area, examining past human activity on the north-eastern lake shore. A previous project in the Lago di Venere area (1998-2002) interpreted the site as a Punic and Roman sanctuary (Audino \& Cerasetti 2004; Cerasetti 2006). Our project complements this and other archaeological investigations of the island's classical past, including the ongoing excavations on the Acropolis, near the main harbour, which have revealed the remains of the island's Punic and Roman centre (Schäfer et al. 2015).

The BUAPP investigates key issues including: the long-term relationship between the Punic and Roman cultures at the Lago di Venere site, situated at a considerable distance from the main areas of cultural interaction around the Acropolis and harbour; the function of the site, be it sacred or profane; and the role of the volcanic crater-lake in the development of the site and the wider environment. For the first two seasons, the project has integrated geophysical survey, excavation and material analyses. In 2014, we conducted survey work. The volcanic nature of the soil excludes the application of some geophysical techniques. As a result, a ground-penetrating radar (GPR) survey was conducted to determine the site's spatial extent and depth, and the appearance of buried features; this is the first archaeogeophysical work undertaken on the island (Urban et al. 2015). Topographical mapping

\footnotetext{
Department of Classics, Brock University, 1812 Sir Isaac Brock Way, St Catharines, ON L2V 4Y6, Canada Joukowsky Institute for Archaeology and the Ancient World, Brown University, 60 George Street, Providence, RI 02912, USA (Email: clive.e.vella@gmail.com)

3 Institute of Archaeology, Cornell University, 261 McGraw Place, Ithaca, NY 14850, USA (Email: tmu3@cornell.edu)

4 Department of Classics and Archaeology, University of Malta, Msida, Malta (Email: maxine.anastasi@ um.edu.mt)

* Author for correspondence (Email: cmurray@brocku.ca)
} 


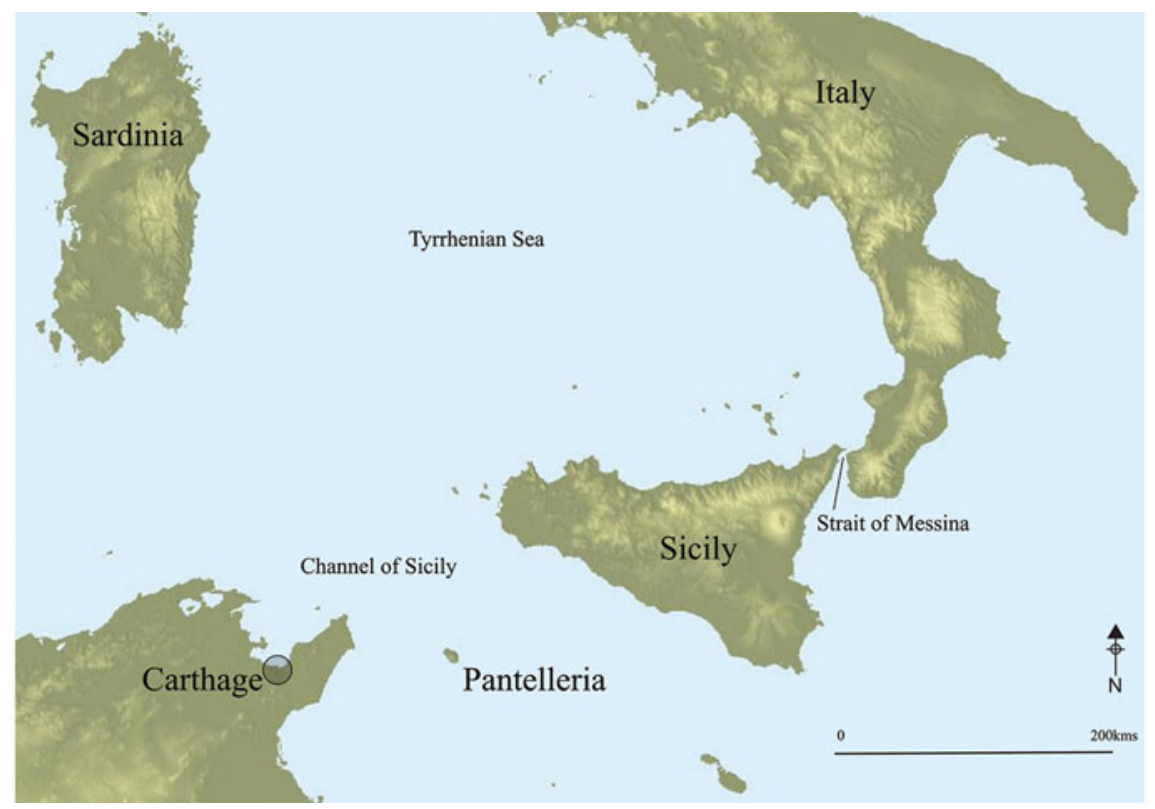

Figure 1. Map showing the location of Pantelleria in the Strait of Sicily.

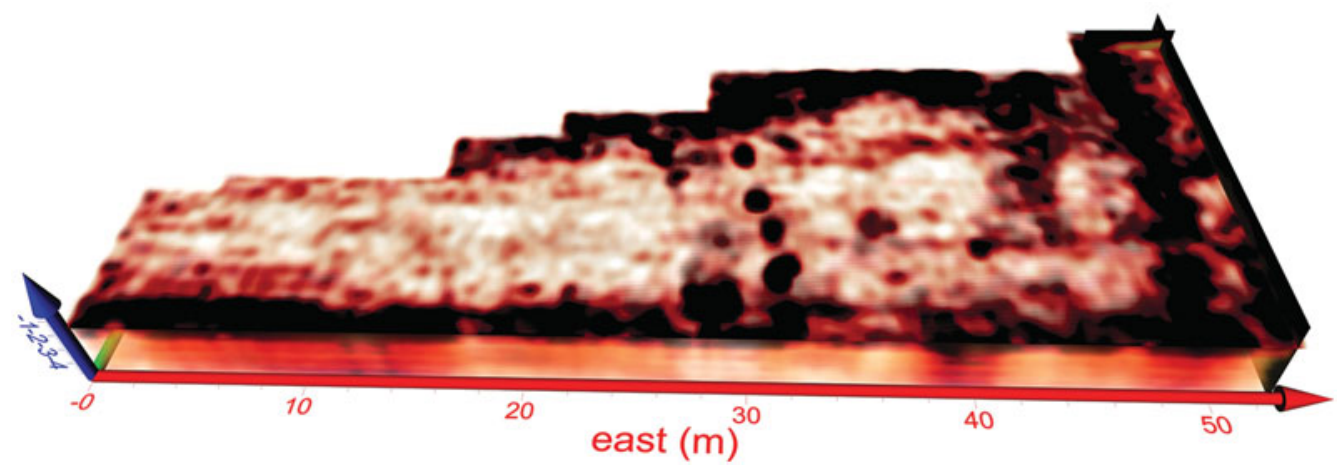

Figure 2. GPR results overview, south of a modern boundary wall and west of the previously investigated area (dark areas represent high amplitude, and light areas represent areas of low amplitude).

was also conducted to record the extent of the site and its broader context. The results of the GPR survey produced clear evidence of an architectural complex measuring approximately $20 \times 30 \mathrm{~m}$, with the remains positioned at $1-2 \mathrm{~m}$ below the surface. There appear to be several interconnected wall features creating rectilinear and curvilinear spaces (Figure 2). The results demonstrate that the extent of the site is much greater than previously believed.

In 2015, four test trenches were excavated to evaluate the significance of the GPR results and to establish cultural and chronological frameworks. The trenches were located in relation to the most significant features identified by the GPR (Figure 3), confirming (C) Antiquity Publications Ltd, 2017 


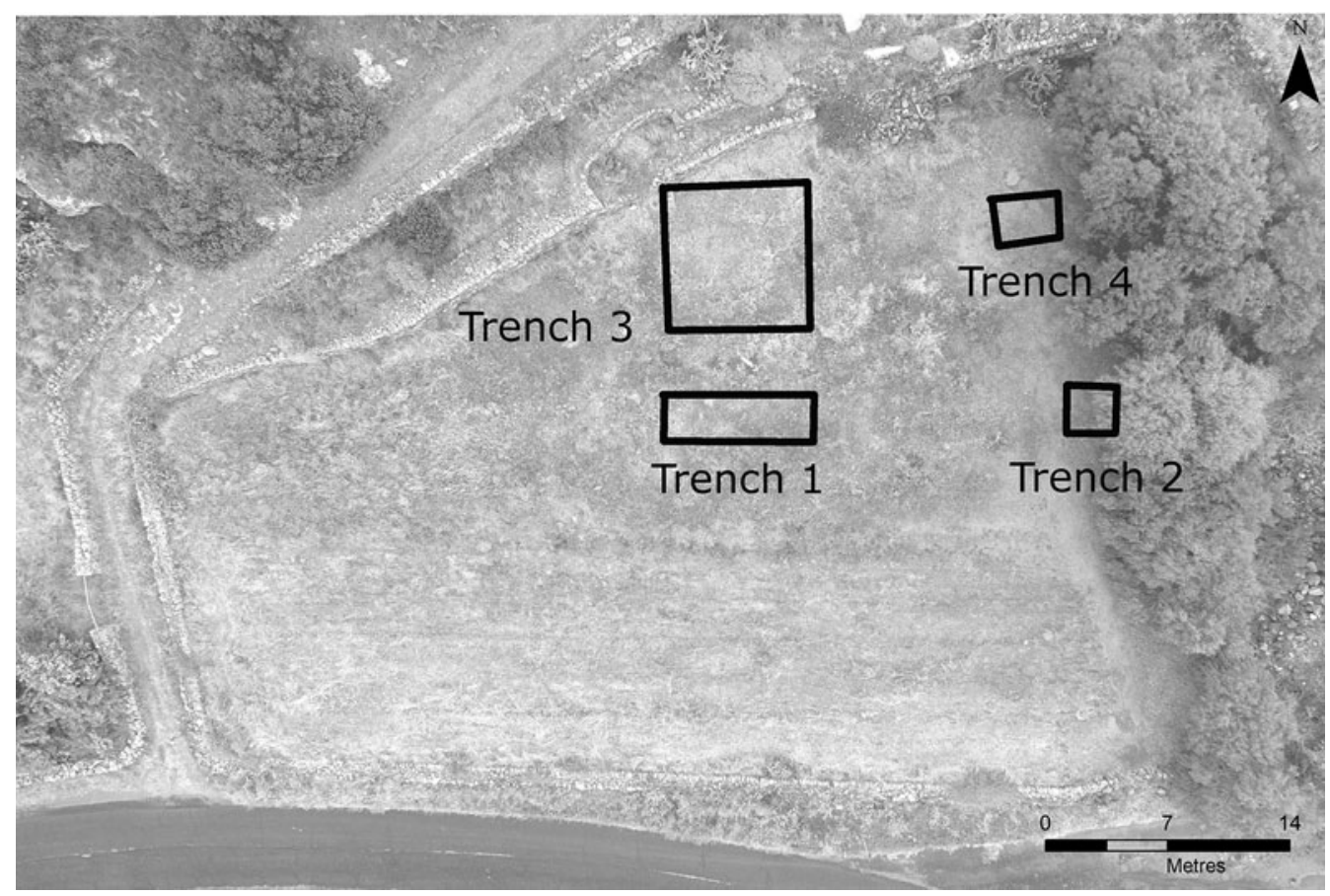

Figure 3. The investigation area of BUAPP, north-east of the Lago di Venere.

the general architectural interpretation. Trench three contained the bottom course of walls constructed of dry-stone masonry with pavimenta punica flooring. The diagnostic pottery dates primarily to the late third to early/mid second century $\mathrm{BC}$, with a small amount representative of the first centuries $\mathrm{BC}$ and $\mathrm{AD}$.

The trenches also revealed an interesting relationship between the natural landscape and the architectural construction techniques. Large areas of natural deposits were found stratified along with the architectural features. After examining the sediments present around the lake edge and within our trenches, it became clear that the volcanic basin, presently only partly filled by the lake, contains a series of natural deposits, possibly arranged in a nesting-bowl configuration. The present lake-bottom consists of white, silty clay that extends outwards, abutting the topsoil across the wider crater area; beneath this is a pinkish gravel layer that was found in all of our trenches; and beneath this is a yellow, silty clay. The previous project at the Lago di Venere interpreted these gravel and sand deposits as natural layers, partly formed by a subsequent rise of the lake water after the ancient period (Manini 2006).

Upon closer inspection, however, the partially exposed structure in trench three revealed the absence of a formal construction foundation (Figure 4). Instead, the exposed southern wall was set directly into the natural layer of yellow, silty clay. In contrast to the earlier project, therefore, we suggest that the pink gravel and yellow clay were pre-existing natural layers used by the Punic and Roman builders. The identification of the lake sediments is important in two ways. The presence of the lake sediments across the site area demonstrates 


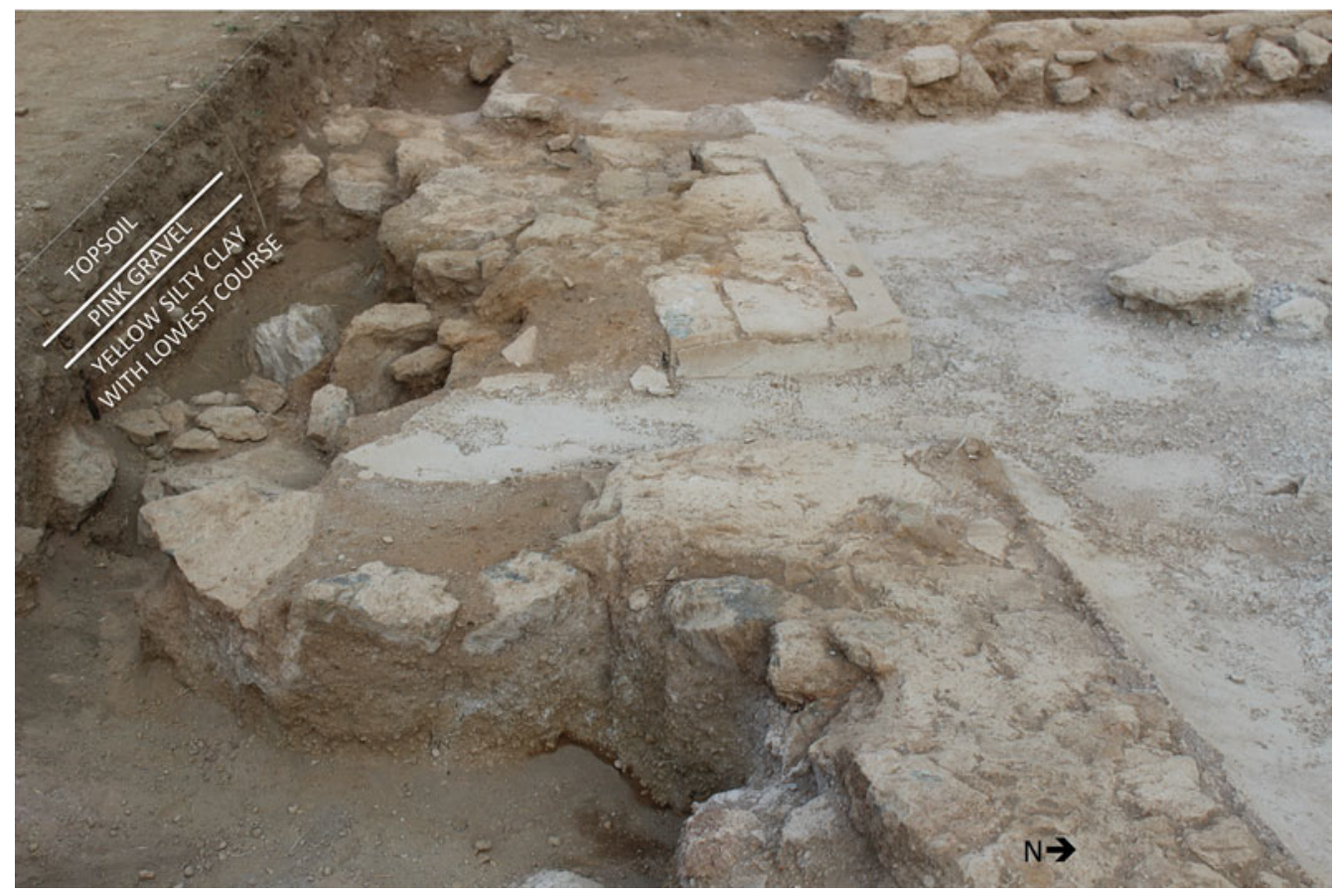

Figure 4. Detailed photograph of trench three looking west. The pink gravel natural deposit overlays the yellow, silty clay natural deposit. Both are cut for the construction of the lowest course of architecture, which does not include foundation trenches.

that, at least at one time, the extent of the lake covered the entire area, probably long before the Punic phase of the site, although this makes it more challenging to determine the chronology of the recession of the lake edge, particularly during the Classical periods. Second, the absence of wall foundations, combined with a construction technique that involves wide wall bases comprised of large blocks for the exterior faces and smaller stones for the internal fill, indicates that a distinctive technique was employed for construction in this unique volcanic landscape.

Our initial findings suggest that there was no significant break in the use of the Lago di Venere and its structures between the Punic and Roman periods, and that the site could therefore represent a rare example of Punic and Roman interaction and continuity. Future fieldwork will help to determine whether the site was indeed a sanctuary, or whether it served a different function, and new environmental studies will concentrate on assessing the role of the lake in the use and significance of the site (pantelleriaproject.org).

\section{Acknowledgements}

The 2014 and 2015 fieldwork seasons were made possible by the generous permission of Paola Misuraca, Soprintendente, and Rosella Giglio, Direttore del Servizio per i Beni Archeologici, at the Soprintendenza per i Beni Culturali ed Ambientali, Trapani, and the support of Brock University, particularly the Humanities Research Institute.

(C) Antiquity Publications Ltd, 2017 


\section{References}

Audino, A. \& B. Cerasetti. 2004. Pantelleria e il culto delle acque: il tempio romano del Lago di Venere, in M. Khanoussi, P. Ruggeri \& C. Vismara (ed.) L'Africa Romana: ai confine dell'impero-contratti, scambi, conflitti. Atti del XV Convengo di Studio: 1139-50. Rome: Collana del Dipartimento di storia dell'Università degli studi di Sassari, Carocci.

Cerasetti, B. 2006. Esplorazioni Preliminari, in E. Acquaro \& B. Cerasetti (ed.) Pantelleria Punica: Saggi critici sui dati archeologici e riflessioni storiche per una nuova generazione di ricerca. Studi e Scavi nuova serie 15: 139-49. Bologna: Ante Quem.
Manini, M. 2006. Della Variabilità dei Suoli in Località 'Lago di Venere', in E. Acquaro \& B. Cerasetti (ed.) Pantelleria Punica: Saggi critici sui dati archeologici e riflessioni storiche per una nuova generazione di ricerca. Studi e Scavi nuova serie 15: 238-45. Bologna: Ante Quem.

Schäfer, T., K. Schmidt \& M. Osanna. 2015. Cossyra I. Die Ergebnisse der Grabungen auf der Akropolis von Pantelleria. Tübingen: Tübinger Archäologische Forschungen.

Urban, T.M., C.A. Murray, C. Vella \& A. LAhiKainen. 2015. Ground-penetrating radar survey on the island of Pantelleria (Italy) reveals an ancient architectural complex with likely Punic and Roman components. Journal of Applied Geophysics 123: 164-69.

https://doi.org/10.1016/j.jappgeo.2015.10.012 